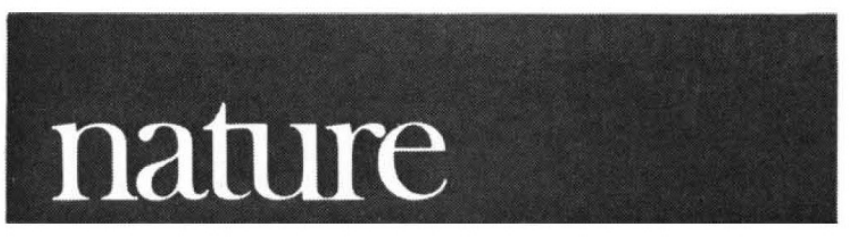

Volume 252

November 8, 1974

\section{Support for Trieste}

THE International Centre for Theoretical Physics in Trieste was established in the early sixties in order to provide a base to which young competent theoretical physicists from developing countries could go occasionally for intellectual exchanges and advanced research. An extensive report on the centre's activities was given earlier this year in Nature of March 22. Much of the early, and indeed continuing success has been due to the manipulations of Abdus Salam, then Pakistan's delegate to the International Atomic Energy Agency (IAEA) and Paolo Budini, professor of physics at the University of Trieste. These two managed to persuade IAEA, the city of Trieste and the Rome government to support a project which encountered a lot of cynicism and disbelief from the scientifically advanced countries. Many felt that helping physicists from technologically backward countries to pursue esoteric research was wasteful of scarce manpower resources. Salam vigorously attacks this point of view by pointing to the alternative open to bright young physicists who discover the exhilaration of research-emigration. 'In a developing country there may be a mere handful of highly skilled academic physicists', he declares, 'They each play a major role in the development of that country's technology, universities and intellectual life. Better far to provide somewhere to recharge their batteries than simply to let them emigrate.'

In the early days the city provided a total of $\$ 1$ million and IAEA gave $\$ 55$ thousand annually. UNESCO started with $\$ 27$ thousand annually and in 1970 moved up to a fuller level of participation. At present the Italian government gives $\$ 350$ thousand, UNESCO, the UN Development Project and IAEA each give $\$ 200$ thousand.

UNESCO support, although modest at first, is, at least formally, ten years old and UNESCO pursues a policy of regarding its financial aid as no more than seed money to get an institution going. After ten years, according to its protocol, the centre should be able to stand on its own feet and find sources of money elsewhere. This is a sound policy for most establishments that UNESCO supports which can go to a specific national government and ask for money. But it is less sound where an institute is used by 90 different nations, the majority poor.

The official British line, which will lead to the delegation expressing their concern at UNESCO this week, is that after ten years there are other deserving projects which could use the $\$ 200$ thousand--itself a large slice of the total UNESCO basic science budget of $\$ 1.5$ million-and so the support should be re-examined. And a $34 \%$ growth rate, they say, is out of line with other growth rates in UNESCO. There is no immediate pressure on Trieste, as it is not proposed to cut funding at once; however in the long run it is clear that the British delegation want Trieste to look elsewhere for their money. Other countries do not see it that way, indeed one or two diplomat-scientists privately express the view that Britain is making herself look foolish by such a gesture at this time. With inflation posing terrible problems for all educational institutions and the rest of the world apparently unready to rock the boat, what causes Britain to take a maverick line?

Partly, no doubt, there is a feeling in the Ministry of Overseas Development (which concerns itself with UNESCO) that the way to help developing countries is through more 'relevant' research. But the prime mover in this affair seems to have been a distinguished scientist himself-Sir Harold Thompson, chairman of the Royal Society UNESCO scientific committee.

It had been clear for some time that Sir Harold intended to urge UNESCO to withdraw from Trieste. His views on the centre (Nature, 243, 136; 1973) were that it was successful, but he did express some concern that international laboratories were being backed by 'well organised pressure groups'. Yet it was not until May 1974 that a group of physicists and mathematicians familiar with the centre was convened by the Royal Society to put their point of view to Sir Harold.

The meeting seems to have been unsatisfactory in that there was no real meeting of minds over the issue. The group, pressure group that it doubtless was, left dissatisfied and with the feeling that the nature of the Trieste centre and the problems that it faces had been barely understood. Trieste's mathematical activities--a recent development--had hardly been appreciated.

As a result, Britain's official viewpoint cannot really be said to be representative of the views of British physicists and mathematicians and seems as much as anything to have emerged from one man's opinion.

The growth rate of $34 \%$ quoted by those who urge re-examination is a mystery. It is a real growth rate, we were assured. And yet UNESCO's contribution has risen only from $\$ 150$ thousand to $\$ 200$ thousand so far in the seventies, and only inflation is permitted to modify this figure before 1976. Hardly a real growth of $34 \%$ and certainly not per annum.

It is, of course, entirely within Sir Harold's rights to press for a strict interpretation of the UNESCO rules if he wishes. But surely when so many others are deeply concerned, an opinion which flies in the face of the advice of fellow scientists is worrying, and a mechanism by which a Royal Society-appointed committee can go to an international meeting with an un-representative view needs examination. And the figures should be right.

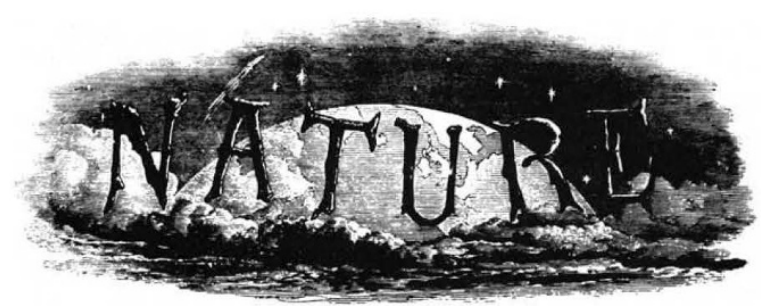

A LARGE monumental fountain, ornamented by the celebrated sculptor Carpeaux, has been erected on the Observatoire Place at Paris. It represents Europe, Asia, Africa, and America rotating the globe, which they carry on their heads, and is very effective; but in spite of M. Le Verrier's protestations, they are rotating the globe from east to west, according to the Ptolemean theory.

From Nature, 11, 36, November 12, 1874. 